\title{
Adolescents and the Challenges in their Motivation
}

\author{
Dr. Denis Çelçima
}

Lecturer in "A. Moisiu "University of Durres/Albania

Abstract

The study has the main object the adolescents and their academic achievements. It aims the determining of the motivation importance (in achievement and the relationship that exist between the dimensions of the internal motivation and the external one. [This instrument is used by the authors: Robert J. Vallerand, Luc G. Pelletier, Marc R. Blais: Nathalie M. Birriere, Caroline B. Senecak; Evelyne F. Vallieres, 1989; 1992]. Self - esteem and also the role of public and private awareness, is established in adolescence, when still in the transitional period the free space facing violated in psychological impact, which require bold initiatives in the field of education.

Keywords: motivation, intrinsic motivation, extrinsic motivation, demotivation, achievement, academic achievement, self efficacy, public awareness, private awareness, parental self - efficacy, teacher self - efficacy.

\section{Introduction}

The main target is:

1. The importance of motivation in academic achievement during adolescence.

2. Impact of extrinsic motivation, which brings expectations to ourselves and boosts hope for success.

Analytical overview of social issues in our time, associated with psychological factors inside and outside the school, which affect children and the mission of the school itself, raise the need for new forms of advanced, if not special needs to a qualitative service change in Albanian society. Different psychologists, mainly Erik Erikson, [Erikson, E. H. 1968] have argued on various psychological needs that individuals have dramatically at different times of their lives. In the case of motivation, research has brought difficulties up to the failure of the education system to meet the students needs, resulting in the decline of motivation and achievement. and so I could Meeting the needs, depends on the level of development of each one. [J Eccles, Adler T, Futterman R, S Goff, J. Meece Kaczala C. \& C. Midgley 1983. p. 78-147].

The complexity of handling performances and positive appearances boost students' motivation not only in academic education, but especially in the formation of their psychosocial personality. This has prompted depth institutional study, against the impact of powerful negative psychological elements which (derive from media, information, poor families and an educational system of non contemporary standards. The study aims at detailing the psychological elements operating in tangible Albanian reality, giving concrete recommendations and remedial effects.

To achieve the proper motivation, we could not be based only on the internal excluding external motivation, self - esteem and the phenomenon of public and private awareness. Many psychologists emphasize the importance of education to learning and personal achievement, as an ego that emanates internally students. On the other hand, the antagonism between intrinsic motivation and remuneration from outside, the (checking and the preventing observations of teachers on academic activities, society and family on the other side, assessing what they have (learnt, and what they (reached to adapt, appears in the form of the show off, to a better or worse behavior and formation.

Motivating teenagers is the big challenge of the school, family and society. Before them today there is a far greater challenge: multi dimensional work in forming and designing of the education in the interest of the future of our society during this transitional period.

In the entire, this study is based on different literature and various authors and experiences. we have managed to use words such as; motivation, intrinsic motivation, motivation outdoor, demoralization, achievement, academic achievement, self - efficacy, public and private awareness, parental self - efficacy, teacher's self - efficacy which in their content give to the material a comprehensive nature of psychological interest in the philosophy of education and in educational system too. 
By living through this developing era, in which the children face the difficulty at home, feel unprotected in front of false information and social network, children with special needs, children in school aiming and struggling for the socialization of their social being, this kind of living will remain the main subject of the qualitative psychological studies against discouragement.

There always be a great effort to support the right of education, against each form of (discrimination, in favour of a suitable education within a school system without dogmatic restrictions and with all of professional service needed for the right psycho - moral education of our students in schools.

\section{Key Terms:}

Achievement $=$ fulfillment and the crowning accomplishment of a goal.

Adolescence $=$ the period of development between childhood and adulthood.

Adolescent egocentrism = the assumption that anyone else experiencing the same way feelings, concerns and opinions of others.

Class management $=$ the creation, provision and maintenance of an enabling environment for the learning process, avoiding various disciplinary problems.

Communication $=$ transmission of a message or messages via speech, gestures different intonation of the voice, eyes and others.

Control = learning strategy, which is used for the examination and control of the learning strategy that serves to gather information on skills and learning among students.

Egocentrism $=$ the assumption that the rest of the world experience in the same way with us.

External motivation $=$ motivation, and rewards arising from external factors .

Identity = the principle that a person or an object remains the same over time and complex answer to the question "Who am l"?

Interaction $=$ different class situations where the teacher and students work together.

Internal motivation $=$ the motivation associated with vetëshpërblyese activities.

Knowledge representation = comparison with what's current in the memory

Motivation $=$ general process through which behavior begins and then it directed towards a certain goal.

Parental self-efficiency = beliefs about personal quality that parents in a particular situation.

Self-efficiency = beliefs about personal quality in a particular situation and beliefs that individuals on their ability to spread the control over their lives.

Teacher self-efficiency = conviction about personal quality that teachers in special situations.

Teaching = action plan, which aims to help individuals in the process of learning.

\section{Motivation in adolescence.}

The researches on motivation have been a mayor component of education psychology for about thirty years so far. Time dictates turn to psychology as the science of knowledge in human behavioral system, which brings induces labor in view of education. The motivation is due to happen when it comes to someones capacity to be shown. Understanding human nature is immense. During these 30 years of great work, it is achieved a lot of knowledge about beliefs, values, aims, motivation and the ways of their development. "The main interest stands in the fact that how the motivation changes during the years of school as there are different factors which make the changes happen. " [Wigfield A. 1994]. Expectancy - value theory of achievement motivation: A developmental perspective. [Educational Psychology Review, 6, 49 - 78] . 
The scientific assessed on reports right to the field of education, it takes precedence and become an integral part of educational work. While monitoring and observation, it succedes (to recommend the object and the subject to whom should apply effective forms and methods of education. Interdependence takes place in space, according to the social and economic conditions, environment, relationships, interactions, which on the other hand bring fundamental differences of individual and collective psychology.

Closer to reality, some issues are based on psychological perspective, the development of thinking skills in problem solving, without underestimating the characteristic features of the social environment. No recommendations can be computed on the Albanian population that reflects differences in connections north - south city - village school youth - youth student in social strata of society. Tradition on the collective psyche brings significant differences in inherited behavior. Implementation of knowledge through testing categorized enables the processing of thought in the field of education, respecting the traditional elements that have persisted.

Processing of thought in education is not only associated with the school. It also summarizes other factors which act through propaganda in social strata, with direct or indirect effects on adolescents. Spontaneity in handling different consequences as social psychology, as well as individual psychology. Towards thought processing function takes advantage of education and the role of institutions, schools, family. The consequences lead to clashes layers with different social interests and inseparable from each - other. The conclusion, banality, de-motivation, barrenness and exposure to crime, in particular; aggressiveness, stealing, prostitution, drug use, teenage pregnancy, school drop etc. Loopholes in the field of education, creates room for abuse, ordinary behavior, gangsterism, which in adolescence are fatal.

The conclusion is straightforward: Albanian society is able reanimation and spiritual crisis between generations is reflected serious consequences in the social life of the country. The situation is reflected on the school, family and society. Problems incurred by adolescents with pain reflected in the family, the teachers, within and outside educational institutions, creating a frightening psychological basis for the future of young people, which is observed with concern the phenomenal effects on individuals.

Reflections on the tasks arising psychological applications in function of education must be directed against the philosophy of consumption. In Albania, this is delicate problem, which so far has been subjected to study, but by preventive recommendations and effective action in the field of education. then:

What is the most effective psycho-pedagogical methodology would be recommended to the school system in the education of generations in Albania?

A sufficient recommendations psychological studies and experiences received from abroad?

A valid comparative lessons 'loaded' serious students with concepts, terms or phenomena that do not belong to the Albanian environment?

Have a goal in itself terminology, vocabulary or other rules, which all costs are reflected as foreign terms that penetrate Albanian daily lexicon?

Why educate so many psychologists in our university, are underestimated as usual contingent when psychology accept that transformation is the basis of overcoming the transition?

Why acquiesce moral and spiritual degradation in the limits of depression, just because of the impossibility of dealing with the problems of life?

What are the ages of adolescence disturbing to show aggressive behavior in criminal boundaries within the school premises, and the extent demotivated teachers and students?

Where it is and where the main interest appears today in the relationship between adolescent students and teachers, as a legislated set of rules in view of educational psychology?

How are conscious orientation toward the vision of transformation of society with high standards, against the return of the phenomenon "of hitting the table with his fist"? 
Where rely impacts of phenomena prohibitive in the past, to the system, to the degree of social intelligence, economic conditions aggravated, or the tendency of importing experiences with spirit scholarly far from reality, where we "produce" psychologists as others?

It is causing concern among teachers dilemma strong today. We can not deny the experience of advanced psychological schools. They "are not making decisions", but regarded as a sampling basis "to understand and implement the decisions of the future". It is important to link effectively with social education of homeless living in Albania, specific action in terms of negative phenomena, which are put face to face with the tradition and heritage aggressively on social psychology in terms of development.

\section{Pedagogical dilemma on Adolescence.}

Not without Purpose treatise start with the teachers. Reaction basis of the study and look at the core of the emergence of psychology, the Need for Practical Implementation of Its Standards, not only for the regulation of teacher Relations - teens, soft to Organize Our consciousness. Protective Against psychic activity aggression behavior, "shouldnt give the Possibility for the Existence and development of harmless". Precisely are the Ones We shouldnt WHO appreciate this, Because in Our mind passes hands and the futures of the nation.

Then, we found a selected line of human behavior in harmony with Our social life and we are Able to Convince this delicate Recognize and admin Their mistakes and beyond to show teens what are the Ways of Appropriate to harmonize individual relationships with the social environment?

We should try to give some explanations about possible solutions for the age group in adolescence, announcing an invitation for discussion for all those who feel they need to give advice and should remember in any case that the word "gold - care", there is distrust of a generation that is experiencing flow of phenomena of the time change is ignored for age, ability and intellect, not braking feelings and psionet for life, there is depersonalization, but is "armor protection" is "protective screen antivirus" immoral fog, which will "catch the spirit" and without realizing it reaches the "blurring" the desire to learn, the desire to knowledge and productive life with personal and social interests.

In this field of study, it is reasonable to treat psychological issues configuration, under development for two periods more subtle; adolescence and early adulthood that, which are a continuation of one - another, after preparation in the first period dominated by the effects of the formation of stable personality as the basis of its presentation in early adulthood.

Seeds of activity school academic and increasing personal wellness, without denying here the concerns school and family, not hinder us to think and judge that their opposite, the impact gradual situations intriguing and seductive, will be Perehera potential risk in system education. Is this the reason why the delicate age, why should I stay away from this type of risk, which will be discusses in detail a little lower. Errors in practical activity study is expensive and they deserve sympathy, but errors in choosing the way of life "can endanger human life itself. "Our goal should press on toward the goal.

So what is the mental activity and the nature of adolescents in social and educational terms?

\section{The psychological impact on the up-bringing}

"Adolescence is a period of transformation of biological, psychological, social and economic". According to the researchers of this age, development stages are:

Early Adolescence (11-14 years),

Middle adolescence (15-18 years),

Late adolescence or youth, it often recognized (18-21).

It is the most emotional periods of life. Individuals interested in sexual and intimate relationships are biologically capable of reproduction. They become smarter, more sophisticated and capable of making decisions. It is known as a transitional stage where childhood is divided by age and during this period, individuals assess those trends that contribute to the production of positive aspects in specific areas, depending on the trends that have. 
In the way of acting of personality based on core impact mechanisms exercise psychology, facing the fierce battle to dominate between the positive side and negativity. Attempts to cultivate calm, a sense of self-restraint and self-control, self-confidence, authenticity, sense of reality, ambition, sense of humor and other qualities of personality, are pitted against shock spiritual sense of the presumption, the sincerity of exaggerated, the rebellion with undue irritability, falling into apathy, aggressiveness due to the feeling of effeminacy, being rated, depression, inability to react to defeat and overcome major environmental stress and social life, etc.

Concept: We all try and "are ready" to give advice. This disease is carried to teachers in judgment "by their" moral recommending behind which lies the desire to change the students according to their abilities and personal feelings, according to the level of culture and professionalism, often without being able and prepared to understand the desires and motivate adolescents to protect and grow to become strong and wise as others, biles more than them. Because the concept inhibitors can not abandon them in their collision with obstacles in life, allowing for inhibiting or distortion of social feelings.

Finding: Seeing and evaluating the existence of social fog it is a very stimulating impetus gradual difficult social situation from which stems variability (relativism) moral. Still missing standard psycho-pedagogical methodologies based on harmony between the rates of duty and individual freedom. As a necessity of social life, it will create in this layer full confidence and adaptation to the environment that surrounds them.

Appreciating the diversity of literature and experiences, culture served the liberal tradition of the best, there are many norms of moral living, written and unwritten, that relying on the basics of education character that apply today and in the tradition of the best, They returned to "standard". They belong to everyone. They can not be changed as appropriate and personal desires.

In these conditions required idealist their assessment and demand for respect of the correct application in everyday life. To avoid the "trauma" is necessary flexibility, variability against constant and permanent self-evaluation. Always, the psychological impact on the stages of change exposes before social strata dilemma that is as much based on the solutions recommended, as opposed assessment unrealistic notion "living democracy": A must maintain a level (means: mass) of certain idealism in the overall assessment of the rates of building social, moral fog that exists today?

\section{Teens contradictions}

In psychological conception will not talk about separation from the rest of the period, but o talk about the stages within it. Erikson believed that ". . . there can be studied adolescence as a period of separate and distinct, rather, those that occur during this age are related to previous events and also have an impact on those who will follow. . . "11. Beyond the borders of adolescence, it is difficult make individual Native and Native encourage irresponsible in the way of evil, as it is difficult in fact that he maintain consciousness facing reality with age problems and concerns.

The way of life that they select, "is not yet clearly defined, a factor that also brings a high degree of uncertainty". ${ }^{12}$ The road is very long and everything moves quickly. Decline able paradepresioni is based on the "slide to life", which amounts to depersonalizojë and distort the far individual path.

Why so extreme? Swipe in life does not come by chance. It "cooked" and operates through active phase factors "shock" of the soul and the subconscious, with very few effects on the opposite reaction. For a wider lookingto what happens in the social environment, compare it to look around every day and feel perhaps unwittingly involved in such a state.

I will try exactly this phenomenon Native to several "zones" psychological action and the period of the emergence of social phenomena (means: negative). These areas display and slide action will be handled in two moments in human development; during adolescence and early adulthood, like two delicate areas of human age.

Three areas of subsidence in life, making their determination:

areas of "suction";

areas "dangerous";

areas "fatal". 
These three areas outlining a "roadmap" simple psychological phenomenon action "slide" to individuals problematic for self, family, school and society.

According to the assessment most likely to accept, areas "suction" includes whole period of the age of adolescence. The area is open to a degree of risk, because at this age "customs" in the limits of subliminal awareness and are not very "specialized" to increase "income" in the treasury of human consciousness. In the area of absorption, it can include two periods of negative action:

The first time, socialization and environmental phenomena of "infected" occurs when the teenager does not keep personal and social spaces. Omissions and adaptation condition assessments and does not shrink "is just a case", "no problem", "I am convinced that he will not repeat again. " These psychic back unwittingly worthless slogans. Self-obstrucion to become transformed him into tolerance without attention to delicate situations, seductive and without realizing it, he has "fallen in. "

The second time, this area is dominated by gradual acceptance of the fact of the situation through selfhandicapping and passivity. In family and social space start "doubts". The problem appears serious and deserves more attention. We are parents, teachers, educators and feel pain when it comes to our children.

"Contradiction" zone is dominated by different links between adolescents. And opinions and feedback can be different too. Parental opinion headache connection is located on the family. Outside this view, if the link between adolescent becomes open discussion of social contradicts and danger, it does not rise to such an extent. Some believe that the link is normal, but if it will be required to accept that their son or daughter to have an affective regard to teens, will certainly shake his head in denial.

Next to an open discussion on this issue, other parents recognize a category dominated by the thought that, "... is only adolescence age of obeying authority of the family and the school. . . "So time obligation. So, the crisis of confidence appears higher when judge within our family. In conditions when the relationship works, very few parents would think that it might be acceptable and not be under a set and abrasive control.

Somehow reactions of the parents are justified: they fear "skid be" consequences that appear with falling output in school, hasty decisions adolescents to their connections, the stress on the lack of income, risk of sexually transmitted diseases, unwanted pregnancies and others. Parental concern is a strong camp. In our argument to soothe concerns would treat the issue in several ways.

First, we will accept and adapt concuring opinion. Ties between adolescents are a natural part of the process of physical growth and the emergence of psychological and physical sensations/ changes. Physical changes is associated with the process of raising awareness. It is when all teenagers spend moments before the mirror, observing the growing body forms, beauty, extension, color of skin, muscle and sexual development, facial cleanliness and others. Satisfaction on physical growth makes it more acceptable in social environment. This promotes shaping relations within the community and show tendencies to "test" them abroad. Within the community there are stronger ties conditioned by distance, the possibility of mutual observation of behavior as elements (of personality.

Second: the impact of adolescent social group is present. Trends to become like others seen in the increasing demand for improved cost-effective dressing for the family. There are other reactions which show the desire not to appear different from others in creating an affective relationship. These "signals" encourage thinking; (". . Why do I have loved. . . ", ". . . what has your friend more than I. . . "; "Although I have to be different, " ect. . In this general situation impacts on age are many that they are interesting detailing. Some boys and girls stay away wishing to establish connection. Later the boys involved in a relationship, partly because not feel safe in connection with the girls not having enough income to pay the bill. A different situation is in the treatment of girls.

Third: family control. The causes of change are legible for parental control that is much stronger. According to them, driven by parental care, they can not be anything other than school route - home. But here excist and other reasons. Some girls are unattractive and rejected, others have not reached sexual maturity, are not interested in relationships with boys, some are so fond of the teachings and under the influence of parents have undergone the concept that "... now is not age for mistress, but only teach and learn. .. ".

Finally, changes in perception are not the result of changes in age, but are the product of other media effects. Young people are facing the effects of "the psychology of the handset", spending hours in front of television screens, 
computer and mobile phones. They consume a good part of the time preferences to the songs, movies, VIPs, drawing, sexual images, communication in social networks and others. Specifications in their mental development of a soap difficult to distinguish between what happens in reality and in life.

In the absence of auxiliary assistance, the real and unreal constitute a problematic combination that undermines the concept of life. They build expectations based on the stories of actors, singers, VIPs favorite. Love of them can be passionate, equally vehement promises, such as in the marketing of the screen. However, the mobile device screen and inexhaustible source of information remain imminent danger of slipping into this age. In many cases now are not valid messages or parents advice, no time to think about how the family's economic situation, they believe that everything can be taken on the electronic network seamlessly.

Psychology of interdependence of means (especially by computer and mobile) has turned man from "man - because" to "man - a consequence". Reports in such conditions parents - children and vice versa, have been hit hard. The situation within the social space have started to establish dominance of the psychology of the vehicle, which has turned into a "kind of rude" quietly and inconvenience caused. Man not only needs to read and meditate, but also be expressed in a language of communication that makes it respected in his social circle. This psychology of returning to "politely" is oriented towards a system of unwritten norms as a guide for action, influenced by a host of anti-values, often justified as "modernism". A social fracture almost (show irreparable consequences.

Today social workers accept that a relationship is a social support and it offer or give more security. Through a link, your son or daughter meet the need for belonging and love and less think to switch to sex. Links adolescence they prepare them for full links early adulthood. They recognized the nature of the connection, acquire skills on how to run a relationship, how to solve conflicts, how to choose the right partner. If "bond " fulfills these functions on adolescent life has no reason to be prejudiced as" heresy "and punished as such.

Reaction and lack of prompt reaction to psychological phenomena of adolescence, are next to each - other but can never claimed it would be hopeful elements to calm yourself in stress-causing teens to their behavior in family and social environments. In this system no one can claim immunity to these phenomena aimed at the phenomenon. As the reaction, as well as has a base reacting. The fact that the individual phenomena in many cases do not occur in the immediate situation, but this phenomena occur gradually fading reaction occur. We may be faced with acute situations, without the possibility of their response.

The second area involves the study in terms of early adulthood to students. This period of change and cornering is associated with high social cost. Within it are found two dangerous moments or periods. Inclusion phase, which is subtle and obvious. Individual, not being able to withstand stress complex, finding no way to adjust against negativity in some climactic moments of life, then "subject to chance" and "collapsing". Without realizing it violates that part of the personality. This is the "sin" to sense the biggest social policy.

The next period is the "gridlock". Put simply, what can you do when it inside? It is the moment of "social coldness", where the family is also evident concern and social environment. So it will be. Evil if "Give it to pick up a finger arm", it aims being. The teenager must become the master of himself and not allow "that Native grabbing". Setbacks will be very difficult. Negative environment attract those who have "invested" and seek "compensation". Sick from drugs, vice, alcoholism, sex, spiritual wickedness to "exercise the trade" they want friends and collaborators. What they now have with you, ye shall ask you to follow suit with others. Continuing a path of no return need money, financial support, resources. ... Therefore be many things, seeking to make "all".

This period carries the anxiety, the fear of moral degradation, open to self - criminality. Meaning: a crime against yourself). "Swipe" has occurred and at "loneliness" psychic distress associated with moral self-hurting. In such situations there is no one not be vetëlutur; "Ah. . . if it was not so"!

In the "fatal phase", punishment is present and expected. He can be moral and legal punishment. In both cases featuring extreme limit of failure of subliminal, awareness, instincts and other psychosocial elements. Ending extreme boundaries of the area in fatal is devastating moment. Recall for a moment the daily events and information: ". . committed suicide, was shot him self, abortion, illegitimate children, prostitution, the drogue, raped, killed her mother in law, killed his wife because he found the boyfriend, crime motives poor, crime within familes. . . ect ". The situation is retaliation against individuals who 
either have slipped in life, or become the subject of her. They have a common denominator: the destruction and spiritual degradation. After this "fatality" peoples are hurt, crushed, destroy and entire families are experiencing anxiety and fear.

Assessing the social situation is necessary to specify some further thought. Analysis of individual flair and everyone is entitled to make a deep and serious analysis to arrived to the roots and to the limits of hurting. Encouraged by teacher selfefficassity, we should do this analysis because it is a necessity to build close connection between reflection, understanding, choices and consequences of the destruction of consciousness and slip into life. This link will help us to "take the turn at the right time. " In favorable environments in school and family, in accordance with the code of conduct will allow distribute this fog immoral and would make life more peaceful and more secure.

Again adolescents driven by public and professional awareness, we should remember the phrase: "Beware that not to be late tomorrow... ".

\section{Few words about psycho-pedagogical methodology.}

The basic contradiction between the stage today displayed the time spent resistance and development trends deserves specific studies. From western and eastern experiences, logic up in the 60's, has proven its contradiction within, relying on basic popular methods of testing and reaching their conclusions. The results are returned in a comparative framework is binding, without appreciating and no deference to its environment, geographical conditions and living spaces.

Assuming the character of complex science in psychopedagogic space or dilemmas presented by the high level of knowledge, the increasing demands of the market social - economic and scientific - research, as well as concerns major regional and global (created by unemployment, demography, ecology), the actors involved in the subject of psychopedagogic study responded educational-forming process and have conducted research based, logical model criteria of time.

Some of the most prominent components enable a more comprehensive focus group methodology in improving teaching and transmitting effective psycho-pedagogical knowledge among adolescents. In addition, researchers can reach the human psyche or teachers oppose themselves to determine everything, or can allow affected by the results of their experiments? How many have to rely on testing methodology and how the study will respect the mature technological methods in the study of human nature and behavior?

Today's criticism to the controversy has yielded results because of social, economic and technological passing them subservient nëndisiplina methods through the application of mathematical systems, the tests, observations and conclusions on the borders of prominent phenomena within human society. "Developing a philosophy of professional training and education" 14 and the math of many disciplines operating in the dimensions of social life, respect the differences and diversity of behavioral action.

It helps to understand and respect the fact that psychology remains dependent to the social development degree, what stage of development that feeds the continuation of active elements in the human psyche. Initially under the age division, psychological science is subject to specific youth-oriented school, what university, youth workers, in different sectors to layer intelligence, targeting their categorization in relation to human behavior.

The issue is simple: Do they have (according to these groups) their psychology of action? The psychology of consumption fails to touch all these layers. Psychology in school is a viable option supported between success and ethical liability categories and freedom.

Historical criteria, both consciously and expressive speaking Methodists laid before the dilemma of education; ". . What happened, what have caused and what to expect in this area vital to our existence and national development; how to overcome it, if education in this phase will include the extraordinary tenderness, harmful, without inside his sense of human love; We will accept the pressure of a tough upbringing imposing strict rules, which would lead to social isolation among adolescents feelings?

Adolescens are 'social creatures' that deserve or need psycho-pedagogical specialists attention. They have their interior "cosmos", trying to explore according to their growing intentions. We need to understand how they see the world and the reality that surrounds them; the ability of perception, memory, imagination, motivation, self-esteem and tendency to build more harmonious relationship interior elements of the human psyche. Putting forward some basic questions: 
How can appear "clashes" between the indications of the reality that surrounds them in relation to the boundaries of the unreal, fantasy and dreams of their own, thus creating empathetic blind belief in the future?

Are they under the influence of hypnotic suggestion and the false splendor and luxury of life on its marketing and due to the demolition of these reports, are dominated by teenagers inferiority complex, or aggressiveness?

How are we able to understand prepare them for life on the basis of psychological characteristics that exhibit in school and social activities?

Does it merely a "psychological game" of parents or teachersor methodists in "huge school book" and the psyche of the adolescent life, or is it a human mission to national values?

What is achieved today through psycho-pedagogical methodology, to provide an opportunity to motivate adolescents with confidence and self-beliefs towards social interests of academic and vocational education?

then:

Against the dictates as moral crisis (dependence and obligation of service to another, eliminating alternatives, closure of trails, placement of barriers, restrictions). It is a phenomenon observed in teaching meaning today, which does nothing except that cultivates inhibiting research and obtaining knowledge among adolescents and stimulates not only attention, but also confusion. This is not enough, as can feed so unconscious aggression and criminal negligence toward oblivion.

Against the loss of rights, denial and rejection leading to teenagers in crisis of social identity. Methodology of education in Albanian education, but the ones methodological takes pedagogical systems (in developed countries, maintains within its system tradition and valuable experience of teaching, based on the basis of a psychology of individual and collective character traditional national, which that distinguishes him in his typology psychopedagogic.

Between these two categories have conflict, as if adolescence or categories of their faculty and educational front, resulting unprepared to cope with the psychological phenomenon.

\section{Conclusions:}

Pedagogical logic and methodology chosen to respect "to strike a fine balance", which harmonizes and creates an environment extremes education for adolescents.

The problem that appears is essential: Do exist any recommended selection based on actual studies to find the "strike a fine balance" of Aristotle in the secondary and university school system, more acceptable to the remedies in service perspective? Determining indicators of the state of operational test are real and they must be respected for the accuracy of conclusions recommending prevention effects in the interest of civic education.

We are looking for solutions to avoid the contradictions in the system of academic training and education.

Without observing the action of economic factors, factors forming and encouraging educational and cultural, environmental impact social issues, relations between tradition, heritage and outlook reports in respect of occurrences national relationship and interaction phenomena imported and influenced by external factors (or just takes and takes as is common in Albanian society) can not be found solutions for overcoming the contradictions that appear in the system of academic and civic education.

Psycho - pedagogical (methodology go beyond the framework of recommendations and return to a field exploration to increase teaching skills.

Deductions in this field can not be given empirically, whether well known names in the field of social psychology, based on the implementation of several programs funded benefits and interest. Methods and achievements often go beyond the frame with compelling effects. Work depth study within social classes and especially within the age group of teens receive special values and important, because on its base Methodists serving the academic and education are free to think and act in unity, without differences generalizations and spontaneous labor imposed by the conditions, circumstances, environment and human content with their specifications.

To respect and harmonize teaching and methodical knowledge within trinomial philosophy - psychology pedagogy. 
Not only under the philosophical divisions, but the actual dimensions have accepted logic given hefty pedagogical value and utility in the field of traditional knowledge and scientific research, classical and modern. This background (phenomena, events and phenomena, the trend, the trend bias) integrated into public and private awareness model takes the value of research in the field of Albanian psychopedagogy. Its dimensions, implied as essentially reasoning (to penetrate the secrecy of incomplete and undisclosed) in this long journey of the model set criteria.

\section{Opposite the "cult" of psychologist, every teacher is a psychologist, educator and Methodist.}

Methodology of establishing and respecting the harmony between human activity and social environment, will support and give a new dimension to research work. Recommendation "not to be unkind, but to be exacting in respect of scientific standards" not to restore to the method of "fist on the table", but in setting up the right and harmonized between coercion and freedom in the educational system of the school, although the difference between them is multifaceted.

Creating the "cult" of psychologist finds it necessary to go in proportion with their appearance as an individual, in harmony and resonance spirits to be near Methodists education, to build with them bridges of communication supporting education of people. Space is full of processed psychology and act in dominance of thought to all strata of society. The short, he knows the psychology of living in the social environment of collective psychology, inside. Educational psychology and does not only schools, but also reading the great book of life that feeds the individual human psyche. Just so you can come to realize "hypnosis" on the adolescent age groups.

In every economic system - social derives a general psychology, which is reflected in the attitude towards life, property, individual and collective human humanism. In Albania there is a phenomenon that occurs in individuals who represent the highest peaks of the acquisition and exercise science of psychology, imposing whatever they disclose to the Albanian social opinion. Our sacred duty is to become architects worthy of the human spirit.

Thanks to systematic work, support and sincere cooperation with colleagues, parents and students, we hope to convey a model and posts needed, which take character recommendation on improving the forms of civic education, academic and family to motivate our children in this period difficult of their lives. Their life is life itself, our greatest spiritual wealth, which is our obligation to safeguard this and guarantee at any price.

\section{References}

[1] Adler Alfred "Të kuptosh natyrën e Njeriut", botim i SHB Fan Noli, Tiranë 2010. Në parathënien e librit.

[2] Adler Alfred "Të kuptosh natyrën e Njeriut", botim i SHB Fan Noli, Tiranë 2010. Në hyrjen e librit f. 3.

[3] Adler Alfred, "Të kuptosh natyrën e Njeriut", botim i SHB Fan Noli, Tiranë 2010. F. 18.

[4] Dr. Denis Celcima, Material studimor i mbrotjes së Doktoraturës: Sfidat e Motivimit në Adoleshencë, UET, Tiranë 2016, f. 127

[5] Dr. Petrit Muka, Mjeshtër Kërkimesh, në vlerësim të botimit: Myra Pollack Sadker, David Miller Sadker, Mesuesit, shkolla dhe shoqëria, Përvojë amerikane bashkëkohore - një mundësi më shumë në procesin e reformimit të shkollës tonë. Tiranë "Eureka" 1995, fq. 4

[6] Erik Erikson, 1968. Identity: Youth and crisis. New York: Norton. Identity and the Life Cycle. [International Universities Press].

[7] Erikson, Youth and crisis. New York: Norton. 1968. Identity and the Life Cycle. [International Universities Press]. fq. 297.

[8] Keniston, 1970, Lipsitz, 1977, Youth: A "new" stage of life. American Scholar, 39, 631 - 641.

[9] Le Bon Gustave, Psikologjia e Rracave, Shtëpia Botuese Reklama, Tiranë 2001. F. 3.

[10] Musai Bardhyl, Psikologjia e Edukimit, Shtëpia Botuese PEGI, Tiranë 1999, në parathënie.

[11] Musai Bardhyl, Psikologjia e Edukimit, Shtëpia Botuese PEGI, Tiranë 1999, f. 89.

[12] Myra Pollack Sadker, David Miller Sadker, Mesuesit, shkolla dhe shoqëria, Përvojë amerikane bashkëkohore - një mundësi më shumë në procesin e reformimit të shkollës tonë. Tiranë "Eureka" 1995, fq. 214.

[13] Steinberg L. 1999, Adolescence (- Fifth (Edition (McGraw - Hill, pp. 10.

[14] Steinberg, 1999, and A. Levine. You and Your Adolescent: A Parent's Guide for Ages 10 to 20. New York: Harper Perennial. 